\title{
AS ESTRATÉGIAS DE RESISTÊNCIA CAMPONESA NA CONTEMPORANEIDADE: Uma análise dos camponeses da Colônia Pulador em Anastácio-MS ${ }^{1}$
}

\author{
CONTEMPORANEOUS STRATEGIES OF PEASANTRY \\ RESISTANCE: An analisys of the peasants from the Colônia Pulador \\ in Anastácio-MS
}

\author{
Simone Maria Leme \\ Professora do Instituto Federal de Mato Grosso do Sul, campus Campo Grande \\ Doutoranda em Geografia pela Universidade Federal da Grande Dourados, MS, Brasil \\ simoneleme_@hotmail.com
}

\begin{abstract}
Resumo
O propósito do presente trabalho é refletir sobre os processos de reprodução camponesa na contemporaneidade, a partir da análise de estratégias de resistência adotadas no interior de unidades de produção camponesa. Como recorte territorial foi selecionado a Colônia Pulador, localizada no Município de Anastácio-MS. Procura-se entender o campesinato a partir do desenvolvimento das relações capitalistas de produção no campo, onde a subordinação camponesa ao capital é vista como uma estratégia de resistência, porém, entende-se que essa subordinação não é um elemento homogêneo no campo, pois acredita-se no desenvolvimento de estratégias de resistência, que possibilitem uma maior autonomia ao camponês. Os camponeses da Colônia Pulador trabalham na terra utilizando a mão-de-obra familiar, e desenvolvem várias estratégias para se manterem na terra, garantindo assim uma autonomia relativa frente a expansão das relações capitalista de produção. Desta forma, entende-se que essa resistência camponesa representa um mecanismo contra a expropriação e proletarização do campesinato. Os camponeses buscam na contradição do modo de produção capitalista estratégias para a reprodução de seu modo de vida.
\end{abstract}

Palavras-chave: Campesinato. Estratégias de resistência. Reprodução camponesa. Município de Anastácio-MS. Colônia Pulador.

\begin{abstract}
The purpose of this paper is to make a reflection about the processes of the peasant reproduction in our contemporary world. It first analyses the strategies of resistance adopted inside the units of peasant production. The Colonia Pulador, located in Anastácio-MS, was selected as the territorial cut. It is our aim to understand peasantry from the viewpoint of the development of the capitalist relationship of land production, where the subordination of the peasants to the capital is seen as a resistance strategy, as it is not a homogeneous element. Also the development of resistance strategies inside the peasant units is believed to ensure some kind of autonomy to the peasants. The peasants
\end{abstract}

CAMPO-TERRITÓRIO: revista de geografia agrária, v. 13, n. 30, p. 92-112, ago., 2018 
from the Colônia Pulador work making use of family labour and have developed a number of strategies to keep working in the land, thus ensuring some relative autonomy to the expansion of the capitalist relationships of production. Thus, such peasant resistance is understood to be a mechanism against the expropriation and proletarianization of the peasantry. By doing so, the peasants make use of the contradiction of the capitalist mode of production to develop strategies that guarantee the reproduction of their lifestyle.

Keywords: Peasantry. Resistance strategies. Peasant reproduction. Anastácio-MS. Colônia Pulador.

\section{Introdução}

A produção camponesa é aquela praticada pelos membros da família, cujo objetivo principal está na satisfação das necessidades básicas da família camponesa. Além disso, o camponês tem autonomia relativa na definição do tempo dedicado a cada atividade, os espaços de produção e a definição das atividades que serão desenvolvidas no interior da unidade de produção camponesa. Diferentemente da produção capitalista que explora mão-de-obra no processo produtivo, com o objetivo principal de obter lucratividade, permitindo assim a reprodução ampliada do capital.

De acordo com Camacho (2014a), o modo de vida camponês não é capitalista, pois sua lógica não está na acumulação de capital e sim na satisfação das necessidades básicas da família camponesa. O princípio da produção camponesa está na reprodução material e cultural da família, que se dá a partir da produção para o autoconsumo e a venda do excedente para aquisição de elementos que não são produzidos na unidade de produção camponesa.

Camacho (2016), analisa a perversidade do capitalismo ao se desenvolver no campo, pois ocorre a combinação da exploração da natureza e da exploração de pessoas, pois esse processo gera mais valia, permitindo a acumulação de capital e a reprodução do sistema, provocando a exclusão e marginalização dos povos e a destruição da biodiversidade, a partir dessa análise o autor sintetiza:

[...] a sobrevivência dos povos do campo e a reprodução de suas relações de trabalho com a terra são, portanto, condição essencial para a manutenção da existência da nossa biodiversidade, tendo em vista que esses povos possuem uma relação com a natureza de respeito e preservação. Pois, a veem como parte inerente de sua sobrevivência e, ao contrário do agronegócio, não enxergam a natureza como fonte de exploração para o lucro. (CAMACHO, 2016, p.07). 
Com a expansão do capitalismo no campo, verifica-se a grande expansão do agronegócio com uma produção voltada para a exportação, altamente tecnificada, com intenso uso de agrotóxicos, assim as paisagens heterogêneas do campesinato são substituídas pelas paisagens homogêneas do agronegócio, intensificando processos de expropriação de camponeses. Porém, o capitalismo ao se desenvolver não elimina todas as relações não capitalistas de produção. Para José de Souza Martins um dos grandes teóricos da Questão Agrária no Brasil, o modo de produção capitalista para se desenvolver não precisa acabar com todas as formas de produção não capitalistas. Pelo contrário, no desenvolvimento do capitalismo sempre haverá o desenvolvimento de relações não capitalistas de produção, como as relações camponesas.

De acordo com Oliveira (1991), o processo de desenvolvimento do capitalismo no campo se realiza em um movimento desigual e combinado. $\mathrm{O}$ capitalismo ao se desenvolver produz relações não capitalistas de produção, ou seja, junto a expansão capitalista temos a criação e recriação de relações não capitalistas de produção. Desta forma, temos a combinação de relações de trabalho familiar de um lado e de outro a expansão capitalista. Segundo o autor, no Brasil, na medida em que aumenta o número de latifúndios capitalistas, há um aumento das unidades de produção camponesa, ou seja, ao mesmo tempo em que aumenta a concentração de terras, aumenta o número de camponeses em luta contra a expropriação.

Os estudos sobre o desenvolvimento do capitalismo no campo encontram-se estruturados em dois paradigmas com concepções teóricas divergentes: tem-se estudos vinculados ao Paradigma da Questão Agrária (PQA) e estudos vinculados ao Paradigma do Capitalismo Agrário (PCA). A tendência campesinista do PQA defende a tese da recriação camponesa, entende que o desenvolvimento do capitalismo no campo se faz a partir de um movimento desigual e combinado. No PCA, a tese principal é da transformação do campesinato em agricultor familiar a partir da integração do camponês ao mercado (CAMACHO, 2014b).

Nesta pesquisa busca-se refletir sobre os processos de reprodução camponesa mediante o desenvolvimento do capitalismo no campo, partindo da análise de estratégias de resistência adotadas no interior de unidades de produção camponesa, nesse sentido parte-se da análise de autores da vertente campesinista do PQA, como recorte territorial foi selecionado a Colônia Pulador, localizada no Município de Anastácio-MS. 
Parte-se da hipótese de que a partir de práticas exercidas pelos camponeses, com objetivo de extrair a renda da terra, utilizando-se várias estratégias de reprodução existentes na contradição do modo de produção capitalista, os camponeses confirmam sua existência e sua reprodução, permanecendo como sujeitos vinculados ao sistema capitalista, embora suas práticas produtivas tratem-se de práticas não capitalistas.

No que se refere a metodologia da pesquisa, após revisão bibliográfica sobre a temática, realizou-se entrevistas semi-estruturadas com 10 famílias camponesas da área de pesquisa, com o objetivo de analisar o modo de vida camponês e as estratégias de resistência adotadas no interior da unidade de produção camponesa.

O campesinato se recria na contradição estrutural do capitalismo, essa recriação pode ocorrer a partir da compra da terra, da luta pela terra e também pela adoção de estratégias internas de resistência ao capital (SHANIN, 2008; FERNANDES, 2007; OLIVEIRA, 2004).

Tendo em vista o avanço do capitalismo no campo, torna-se necessário analisar a reprodução do campesinato a partir da sujeição da renda da terra ao capital. No capitalismo esta sujeição pode ocorrer de duas formas: a partir da territorialização do capital no campo, e a partir da monopolização do território pelo capital (OLIVEIRA, $1981 ; 1992)$.

A desterritorialização do campesinato ocorre a partir da territorialização do capital no campo, neste processo ocorre a homogeneização dos espaços a partir o avanço do agronegócio, neste cenário o camponês é totalmente expropriado, migra para outra região ou se proletariza.

Quando ocorre a monopolização do território pelo capital, ao contrário da territorialização do capital, o camponês permanece no campo, porém subordinado a uma lógica capitalista de produção, neste cenário o camponês entrega sua produção ou parte dela para a agroindústria, esse processo permite a permanência e reprodução camponesa frente ao avanço do capitalismo no campo.

De acordo com Moura (1988), no capitalismo o camponês controla a terra sem ser dono do capital. A expansão da agroindústria tem nos últimos anos transformado o camponês em um trabalhador para o capital, sem transforma-lo em operário, o que chama a atenção nos últimos anos é a subordinação do camponês ao capital. Assim sendo, os estudos do campesinato na contemporaneidade trazem a subordinação camponesa, como 
sendo uma estratégia de resistência tendo em vista o grande avanço do capitalismo no campo e as consequências deste processo para os povos da terra e para o meio ambiente.

Procura-se nesta pesquisa entender o campesinato a partir do desenvolvimento das relações capitalistas de produção no campo, onde a subordinação camponesa ao capital é vista como uma estratégia de resistência, porém, entende-se que essa subordinação não é um elemento homogêneo no campo, pois acredita-se no desenvolvimento de estratégias de resistência adotadas no interior das unidades camponesas que possibilitem uma maior autonomia ao camponês.

A seguir realiza-se um diálogo entre as divergentes leituras dentro dos paradigmas da Questão Agrária e do Capitalismo Agrário, dando ênfase as teses de reprodução camponesa no capitalismo a partir do Paradigma da Questão Agrária; na sequência apresenta-se uma discussão conceitual sobre as estratégias de resistência do campesinato, com o objetivo de caracterizar o modo de vida camponês e os processos de reprodução camponesa no capitalismo; e por fim será apresentado os resultados das análises realizadas no recorte territorial selecionado, para a partir dessas análises compreender como o campesinato se reproduz no capitalismo e as estratégias adotadas para sua reprodução.

\section{Diferenças paradigmáticas: O PQA e a recriação camponesa}

De acordo com Fernandes (2007), os estudos sobre o desenvolvimento do capitalismo no campo estão estruturados em dois paradigmas com concepções teóricas divergentes: estudos que partem do Paradigma do Capitalismo Agrário (PCA), e estudos que partem do Paradigma da Questão Agrária (PQA).

Os estudos do PCA abordam o desenvolvimento territorial do campo somente na perspectiva da reprodução das relações capitalistas de produção, não analisando as contradições e conflitualidades do sistema, analisam as transformações dos camponeses em agricultores familiares, totalmente integrados e desenvolvendo uma lógica capitalista de produção, portanto para esse grupo de pesquisadores, os camponeses não existem, ou estão condenados ao desaparecimento em meio ao desenvolvimento capitalista no campo. No Brasil o Paradigma do Capitalismo Agrário tem como principal representante Ricardo 
Abramovay, e sua tese de doutorado publicada em 1992 com o título "Paradigmas do Capitalismo Agrário em Questão" (CAMACHO, 2014b p.114).

Os estudos do PQA, abordam o desenvolvimento territorial do campo a partir das críticas ao capitalismo, tendo como referência as contradições e as conflitualidades entre as relações capitalistas e não capitalistas de produção. O PQA apresenta duas vertentes marxistas divergentes, a proletarista (que desenvolve análises relacionadas ao fim do campesinato a partir da proletarização) e a campesinista (que desenvolve as análises de reprodução, recriação e resistência camponesa) (CAMACHO, 2014b).

Considerando esses paradigmas temos três bases de discussões na geografia agrária: as análises relacionadas ao fim do campesinato a partir da proletarização (Paradigma do Questão Agrária); as análises de reprodução, recriação e resistência camponesa (Paradigma do Questão Agrária); e as análises de transformação do camponeses em pequenos agricultores capitalistas (Paradigma do capitalismo Agrário) (CAMACHO, 2014b).

A vertente proletarista do Paradigma da Questão Agrária é formada por teóricos do marxismo Ortodoxo como Karl Kautsky e Vladimir Lenin, que teorizaram em suas obras o fim do campesinato, a partir do pleno desenvolvimento das forças produtivas no campo, ocorrendo assim a proletarização, sendo uma condição necessária para alcançar o socialismo (CAMACHO, 2014b).

Para Kautsky (1980), o fim do campesinato estava anunciado, em virtude da formação de uma classe proletária e uma burguesa, a partir do desenvolvimento de relações capitalistas no campo. Haveria um processo de industrialização no campo, resultante do uso de maquinários, insumos e técnicas modernas, esse processo resultaria na modernização do campo e a evolução para a constituição de empresas rurais, provocando a total expropriação do camponês.

Lenin (1985) acreditava que a expansão das relações capitalistas de produção levaria à diferenciação social campesina, ou seja, os camponeses que obtivessem renda se tornariam pequenos capitalistas (camponeses ricos) e outros tenderiam ao empobrecimento e à proletarização. O mercado interno no capitalismo é resultado de seu processo de desenvolvimento, que aprofunda a divisão social do trabalho e transforma camponeses em capitalistas e operários. 
Interessante destacar, que no Brasil a diferenciação social do campesinato ocorre, porém esse não é um elemento linear no campo brasileiro, e não implica na extinção camponesa, contrariando assim as análises realizadas por Lenin. Desta forma, identificamos a permanência de várias categorias de camponeses, uns mais subordinados ao capital, outros menos, porém esses sujeitos se mantém como camponeses, reproduzindo seu modo de vida.

A vertente campesinista é formada por teóricos do marxismo que defendem a reprodução e resistência camponesa, partindo da tese do desenvolvimento desigual e combinado do capitalismo no campo, que tem provocado a expropriação de um lado (desterritorialização) e a luta e resistência de outro lado, conduzindo a territorialização e reterritorialização camponesa (CAMACHO, 2014b).

Dentro da vertente campesinista pode-se destacar o clássico Alexander V. Chayanov (1974). Sua obra constitui uma importante referência para entender a caracterização campesina no núcleo familiar a partir da teoria do balanço trabalhoconsumo na unidade doméstica, onde a intensidade do trabalho praticado por cada membro da família, é medido a partir do equilíbrio da relação existente entre braços versus bocas, ou seja, membros aptos ou não ao trabalho. Quando há mais bocas do que braços, a intensidade do trabalho aumenta, porém quando os membros não aptos se tornam aptos ao trabalho o equilíbrio é estabelecido.

Partindo da teoria do balanço trabalho-consumo na unidade doméstica, Chayanov (1974), analisa a proletarização temporária do camponês como uma estratégia de reprodução camponesa, desta forma em alguns momentos para atender o equilíbrio entre o trabalho e as necessidades básicas, o camponês pode se ocupar em outras atividades fora da unidade de produção campesina, com o objetivo de garantir sua reprodução. Desta forma, para esse autor, os camponeses se inserem no sistema econômico dominante, sendo capazes de adaptar-se às regras gerais da formação econômica vigente e se reproduzirem enquanto camponeses.

Teodor Shanin é outro teórico da vertente campesinista. Para Shanin (2008), a natureza da economia camponesa revela a flexibilidade de adaptação ao modo de produção dominante. Os elementos fundamentais da organização camponesa tem por objetivo a reprodução de seu modo de vida, e não a acumulação de capital como na lógica capitalista de produção. $\mathrm{O}$ autor destaca em sua obra a multiplicidade de soluções 
encontradas para enfrentar crises, como sendo um elemento de natureza da economia familiar camponesa, que é muito distinta de outras formas de economia, como a capitalista, o autor destaca também a eficiência da economia campesina:

\begin{abstract}
A economia familiar tem seus próprios modelos, suas próprias estruturas e seu próprio significado primordial que não desaparece. Por isso, sob certas condições, a economia camponesa é mais eficiente do que economias não-camponesas. Os membros da família e o modelo familiar básico de bem-estar econômico estão envolvidos de forma particular num sistema de uso do trabalho que não é assalariado, mas trabalho familiar. Daí a sua capacidade para resolver problemas que outros tipos de economia não resolveriam de uma maneira tão eficaz e pouco dispendiosa. (SHANIN, 2008, p.27).
\end{abstract}

Para Shanin (2008), o campesinato precisa ser estudado, não que fato de precisarem de ajuda, mas pelo fato de poderem ajudar a população como um todo, pois esses sujeitos sociais possuem muitas habilidades, características internas que precisam ser repassadas para a população não camponesa. Os camponeses conseguem resolver problemas, que a maior parte da população esta envolvida, com muita criatividade desenvolvem uma multiplicidade de soluções para contornar momentos de crise.

No Brasil entre os teóricos da vertente campesinista do PQA se destacam José de Souza Martins, José Vicente Tavares dos Santos, Ariovaldo Umbelino de Oliveira e Bernardo Mançano Fernandes. Partindo das análise de autores nacionais e internacionais, como Shanin, acredita-se na necessidade de compreender a posição do sujeito camponês no processo de reprodução capitalista, e a necessidade de discutir políticas públicas que possibilitam ao camponês mais qualidade de vida e autonomia para uma reprodução digna e não excludente, desta forma, defende-se a necessidade de políticas públicas planejadas a partir do Paradigma da Questão Agrária dentro da vertente campesinista desse paradigma, só assim teremos uma menor desigualdade social no campo com uma distribuição mais justa de renda.

\title{
As estratégias de resistência camponesa
}

Os elementos que caracterizam a (re)produção camponesa, são tratados em obras de autores clássicos e contemporâneos. No Brasil, Tavares dos Santos (1978), em sua obra "Os colonos do vinho", apresenta oito elementos estruturais da produção camponesa, 
esses elementos caracterizam as unidades de produção camponesa e alguns desses elementos representam estratégias de resistências adotadas com o objetivo de garantir a reprodução da família camponesa, são esses os elementos analisados por Tavares dos Santos:

1 - A Força do trabalho familiar: na unidade de produção camponesa o trabalho é desenvolvido pelos membros da família aptos ao trabalho, marido, mulher e filhos, todos são envolvidos no processo produtivo.

2 - A prática da ajuda mútua: é muito comum entre as unidades de produção camponesa, camponeses que ajudam seus amigos, vizinhos e familiares, nas práticas de produção que exigem mais mão-de-obra, como o plantio, a colheita, a limpeza dos pastos, entre outras atividades. Pode também ocorrer a prática de troca de dias de trabalho entre as unidades de produção camponesa.

3 - O Trabalho acessório: ocorre com o objetivo de garantir as necessidades básicas da família, onde o camponês periodicamente se torna um assalariado, com o objetivo de complementar a renda familiar, isso pode ocorrer quando sobram braços ou quando o rendimento é insuficiente para garantir a reprodução da família. A prática do trabalho acessório é uma estratégia de resistência que permite a manutenção da família camponesa na terra, evitando a total proletarização.

4 - A Força do trabalho assalariado: em alguns casos pode ocorrer a contratação de mão-de-obra em alguns períodos, principalmente quando o número de braços não é o suficiente para as atividades realizadas na unidade de produção camponesa.

5 - A socialização do camponês: o camponês transfere seus conhecimentos para os mais novos, como o objetivos de reproduzir seus costumes e seu modo de vida. No mundo do campesinato essa prática garante a reprodução do modo de vida camponês que será repassado de geração em geração.

6 - A propriedade da terra: os camponeses são proprietário da unidade de produção, possibilitando a família camponesa mais autonomia para a organização das atividades produtivas desenvolvidas dentro da unidade de produção.

7 - A propriedade dos meios de produção: além de proprietário da terra, os camponeses também possuem seus instrumentos de trabalho.

8 - A jornada de trabalho: sendo proprietário da terra e possuindo seus instrumentos de trabalho, o camponês possui autonomia na definição de sua jornada de 
trabalho, que pode variar de acordo com a época do ano, e com as atividades desenvolvidas na unidade de produção camponesa, desta forma, o tempo do camponês difere do tempo do proletariado assalariado, visto que o camponês é um sujeito autônomo na definição do tempo dedicado a cada atividade.

Esses elementos apresentados por Tavares dos Santos, caracterizam o campesinato, e representam algumas estratégias de resistência adotadas pelos camponeses. Como abordado por Shanin (2008), os camponeses desenvolvem uma multiplicidade de soluções para contornar momentos de crise, através do trabalho acessório o camponês se torna assalariado para garantir a reprodução da família camponesa, essa proletarização não descaracteriza o campesinato, pois o dinheiro que entra na economia camponesa a partir do assalariamento, será utilizado para a compra de produtos não produzidos na unidade de produção, e para a compra de instrumentos de trabalho, que são fundamentais para a reprodução da família camponesa.

No contato com o mercado o camponês também desenvolve várias estratégias para a reprodução de sua família. A relação camponesa com o mercado acontece de maneira distinta se comparada aos produtores capitalistas, devido à especificidade do modo de produção, pois ainda que parte da produção seja destinada ao mercado, esse sujeito a faz para garantir melhores condições de reprodução de sua família. Desta forma, segundo Oliveira (1991), o movimento da produção camponesa está expresso na formula M-D-M, onde se tem a conversão de mercadoria em dinheiro e a conversão do dinheiro em mercadoria.

Com relação à produção simples de mercadoria do campesinato, Tavares dos Santos (1978) nos explica que:

[...] O camponês é personificação da forma de produção simples de mercadorias, na qual o produtor direto detém a propriedade dos meios de produção - (terra, objeto de trabalho e outros meios de trabalho) - e trabalha com estes meios de produção. Esta combinação de elementos faz com que o camponês se apresente no mercado como vendedor dos produtos do seu trabalho, como produtor direto de mercadorias. Como produtor, venderá seus produtos para adquirir outros, qualitativamente diferentes, que possam satisfazer suas necessidades de consumo individual ou produtivo. (Tavares dos Santos, 1978, p. 69).

Para Fabrini (2006), a produção para o autoconsumo e a produção mercantil simples, representa uma autonomia para o campesinato, pois os camponeses são 
produtores diretos de seus próprios meios de vida. A produção de resistências perfaz o cotidiano camponês, práticas como a agricultura orgânica, e a utilização de métodos naturais para o controle de pragas, faz com que os camponeses implementem uma agricultura defensiva com relação ao uso dos agrotóxicos, e de outros insumos. A implementação de conhecimentos técnicos elaborados pelos próprios camponeses, permite ao camponês uma menor dependência do mercado capitalista para a aquisição de implementos agrícolas.

A diversidade da produção camponesa também representa uma estratégia de resistência, alguns produtos são produzidos apenas para o autoconsumo da família, outros são produzidos para atender o mercado, quanto mais diversa é a produção, menos o camponês precisará depender do mercado para a compra de produtos.

As formas de comercialização também indicam a autonomia do campesinato, e podem representar estratégias de resistência, favorecendo assim a reprodução camponesa, quando a produção é entregue diretamente a empresas capitalistas ou a atravessadores, o camponês transfere parte de sua renda ao setor capitalista. A participação de camponeses em feiras municipais, onde o camponês vende seu próprio produto ao consumidor, é uma forma de conquista de autonomia, pois neste caso não haverá transferência da renda camponesa aos setores capitalistas.

No campesinato podemos encontrar várias estratégias adotadas para a conquista de uma maior autonomia. Os camponeses brasileiros são diversos, porém, apesar desta diversidade os camponeses possuem elementos que identificam sua unidade. Toda essa diversidade do campesinato possui uma centralidade do papel da família na organização da produção e na constituição de seu modo de vida, a partir do trabalho na terra.

\section{As estratégias de resistência camponesa na Colônia Pulador}

A Colônia Pulador está localizada no município de Anastácio-MS (Mapa 01), aproximadamente $12 \mathrm{~km}$ da sede municipal. O Município de Anastácio faz limite ao norte com o Município de Aquidauana, sendo que as áreas urbanas desses municípios formam uma área contínua, cujo limite natural é o Rio Aquidauana. 
Mapa 01 - Localização da Colônia Pulador no Município de Anastácio - MS.

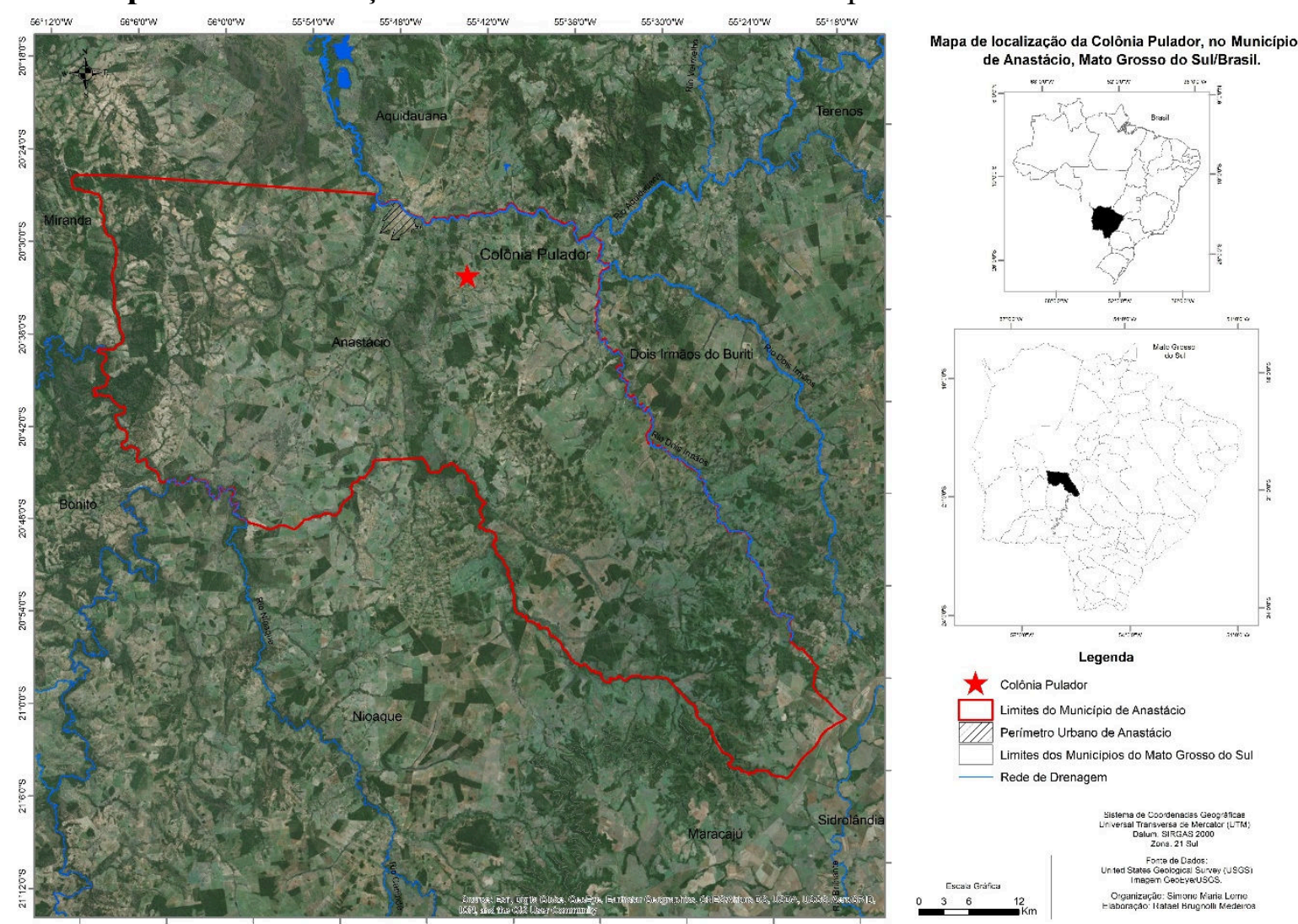

Os moradores da Colônia Pulador, tratam-se em sua maioria de migrantes nordestinos e seus descendentes, que se estabeleceram na região no início do século XX. A unidade de produção camponesa da Colônia Pulador, se materializa por meio da relação terra, família, trabalho. Atualmente, além de nordestinos e descendentes, na colônia, também encontramos paulistas e sulistas que compraram terras na região na segunda metade do século XX e início do século XXI.

No início do processo de formação territorial da Colônia Pulador, a produção básica voltava-se para a plantação da mandioca, com o principal objetivo de produzir a farinha de mandioca. Ao longo do século XIX foram abertas várias "casas da farinha" na Colônia. A chamada “casa da farinha”, é um local onde a farinha de mandioca é produzida com a utilização de instrumentos artesanais. Atualmente, são poucas as famílias que produzem farinha de mandioca na Colônia. No final do século XX e início do século XXI a migração de camponeses paulistas e sulistas para a colônia contribuiu para a diversificação da produção atual. 
O tamanho das propriedades que foram entrevistas, na Colônia Pulador, variam entre 03 a 38 hectares, e a aquisição das propriedades foi realizada a partir da compra ou herança. A produção da Colônia Pulador é muito diversificada, nas entrevistas os seguintes produtos foram relacionados: mandioca, farinha de mandioca, polvilho de tapioca, massa puba (massa extraída da mandioca fermentada, largamente utilizada na produção de bolos, biscoitos e diversas outras receitas), criação de galinha e produção de ovos de galinha, criação de gado, produção de leite e queijo, hortaliças, peixe, banana, extração da castanha do baru (fruto do baruzeiro, árvore nativa do Cerrado brasileiro, sua castanha é muito utilizada na culinária brasileira), extração do urucum (fruto do urucuzeiro, árvore nativa da América Tropical, seu fruto é muito utilizado como corante e pela indústria farmacêutica), maxixe, quiabo, abóbora, abacaxi, laranja, manga e limão.

Os produtos são destinados ao autoconsumo da família e alguns são destinados à comercialização nas cidades de Anastácio e Aquidauana, com o objetivo de adquirir produtos que não são produzidos dentro das unidades de produção, e para a compra de insumos e equipamentos utilizados na produção. No Quadro 01, apresenta-se os produtos produzidos para a comercialização e as formas de comercialização das unidades de produção entrevistadas.

Os camponeses possuem a capacidade de desenvolver uma série de estratégias para a permanecer na terra de trabalho. Uma estratégia adotado pelos camponeses é o aumento da quantidade e da qualidade do que é produzido internamente (o beneficiamento dos produtos é um exemplo desta estratégia). Na Colônia Pulador, podemos citar como exemplos de beneficiamento de produtos a produção da farinha de mandioca e de outros derivados da mandioca, e a produção de derivados do leite, como o queijo e o requeijão. 
Quadro 01 - Colônia Pulador: Produtos produzidos para a venda e formas de comercialização

\begin{tabular}{|c|c|c|c|}
\hline $\mathbf{U P}$ & $\begin{array}{l}\text { Tamanho da } \\
\text { propriedade } \\
\text { (hectares) }\end{array}$ & Produtos produzidos para a venda & Formas de comercialização \\
\hline 01 & 4,5 & $\begin{array}{l}\text { Mandioca com casca e sem casca; } \\
\text { Derivados da mandioca (Farinha de } \\
\text { mandioca tradicional e temperada, } \\
\text { polvilho, massa puba e colorau feita } \\
\text { da farinha de mandioca; Castanha do } \\
\text { cambarú torrada; e Frutas e legumes } \\
\text { (Banana, maxixe, quiabo, abóbora, } \\
\text { abacaxi, manga, laranja e limão). }\end{array}$ & $\begin{array}{c}\text { Feira Municipal de Anastácio; } \\
\text { Entrega em comércios da área } \\
\text { urbana de Anastácio e } \\
\text { Aquidauana. }\end{array}$ \\
\hline 02 & 06 & $\begin{array}{c}\text { Farinha de mandioca tradicional e } \\
\text { temperada. }\end{array}$ & $\begin{array}{l}\text { Mercadão Municipal de } \\
\text { Aquidauana. }\end{array}$ \\
\hline 03 & 23 & $\begin{array}{c}\text { Queijo; Ovo caipira; Porco; e Cheiro- } \\
\text { verde. }\end{array}$ & $\begin{array}{c}\text { Entrega em comércios da área } \\
\text { urbana de Anastácio e } \\
\text { Aquidauana; Venda na } \\
\text { unidade de produção. }\end{array}$ \\
\hline 04 & 09 & $\begin{array}{l}\text { Leite; } \\
\text { Farinha de mandioca tradicional. }\end{array}$ & $\begin{array}{c}\text { Laticínio; } \\
\text { Entrega em comércios da área } \\
\text { urbana de Anastácio e } \\
\text { Aquidauana. }\end{array}$ \\
\hline 05 & 18 & Leite. & $\begin{array}{c}\text { Entrega em residências da área } \\
\text { urbana de Anastácio e } \\
\text { Aquidauana. }\end{array}$ \\
\hline 06 & 38 & $\begin{array}{l}\text { Queijo; Requeijão; e Ovos de } \\
\text { galinha. }\end{array}$ & $\begin{array}{c}\text { Entrega em residências da área } \\
\text { urbana de Anastácio e } \\
\text { Aquidauana. }\end{array}$ \\
\hline 07 & 03 & Queijo. & $\begin{array}{c}\text { Entrega em residências da área } \\
\text { urbana de Anastácio e } \\
\text { Aquidauana. }\end{array}$ \\
\hline 08 & 12 & Farinha de mandioca tradicional. & $\begin{array}{l}\text { Mercadão Municipal de } \\
\text { Aquidauana. }\end{array}$ \\
\hline 09 & 10 & Leite & $\begin{array}{c}\text { Entrega em residências da área } \\
\text { urbana de Anastácio e } \\
\text { Aquidauana. }\end{array}$ \\
\hline 10 & 20 & Leite & Laticínio. \\
\hline
\end{tabular}

Fonte: Pesquisa de campo, 2018.

Outra estratégia adotada pelo campesinato é a redução dos custos da produção, a partir da utilização de recursos internos à unidade de produção, e a diminuição do que é adquirido no mercado. Como exemplo, podemos citar a produção da "farinha de mandioca temperada", este produto é vendido por um preço maior no mercado, e para produzi-lo utiliza-se apenas de temperos produzidos na unidade de produção. 
Na Colônia Pulador, as formas de comercialização são diversas: alguns camponeses comercializam seus produtos na Feira Municipal de Anastácio (Fotos 01 e 02), realizada todas as sextas-feiras; outros possuem clientes fixos fazendo entregas em residências e em comércios das cidades de Aquidauana e Anastácio (Foto 03); e a produção do leite é direcionada aos laticínios da região.

A diversidade da produção e as formas de comercialização dos produtos, são fatores que possibilitam medir diferentes níveis de autonomia entre as unidades de produção camponesa do Pulador. Podemos analisar uma autonomia relativa entre as unidades de produção camponesa.

A apropriação da renda da terra pelos camponeses garantem a reprodução de sua família, essa apropriação é medida a partir das relações de comercialização dos produtos, garantindo que essa apropriação não seja realizadas por setores capitalistas, portanto os instrumentos de comercialização dos produtos são fundamentais para a análise da autonomia do campesinato.

Foto 01: Barraca de camponês da Colônia Pulador na feira municipal de Anastácio.

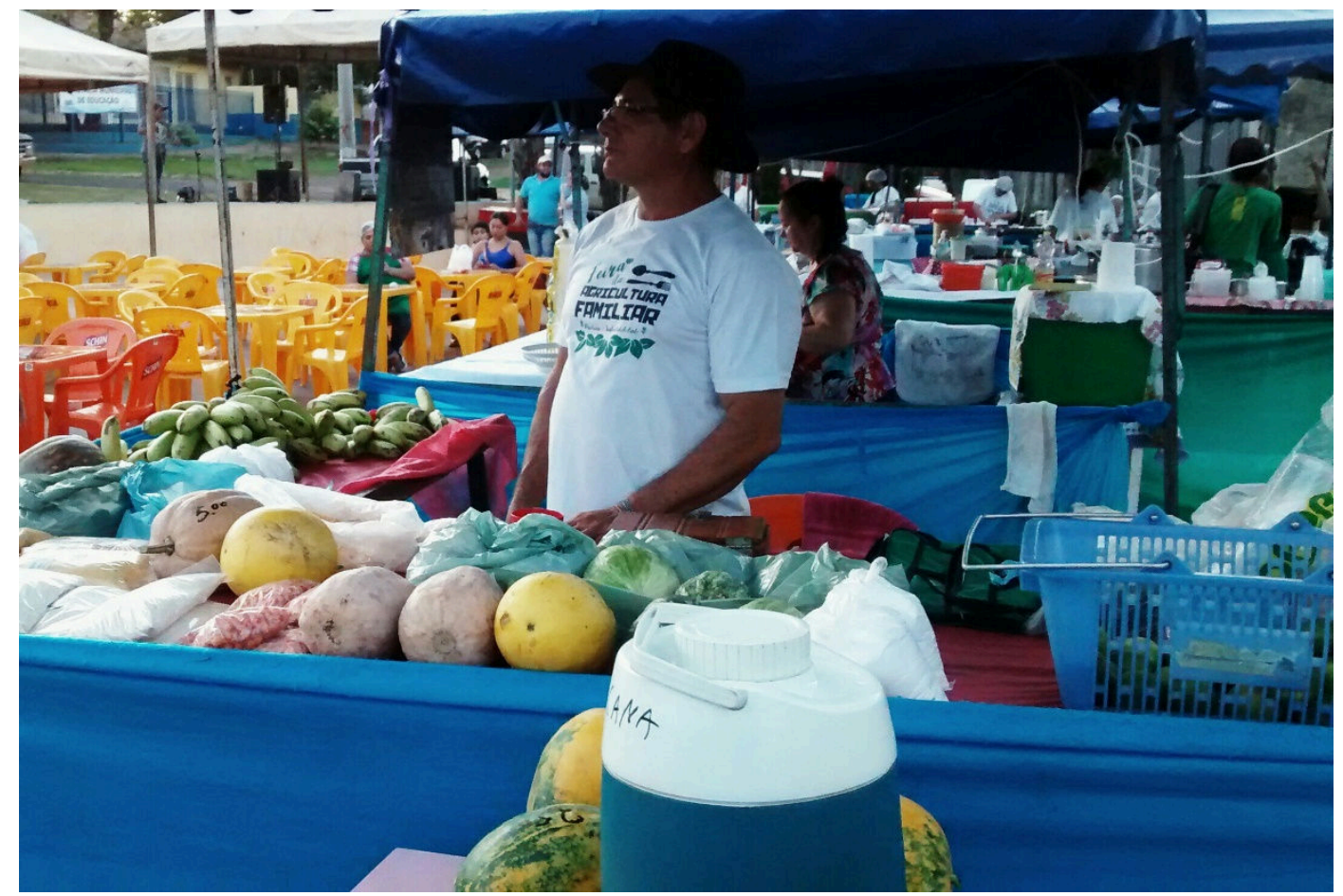

Foto: Leme, 2018. 
Foto 02: Produtos em barraca de camponês da Colônia Pulador, na feira municipal de Anastácio.

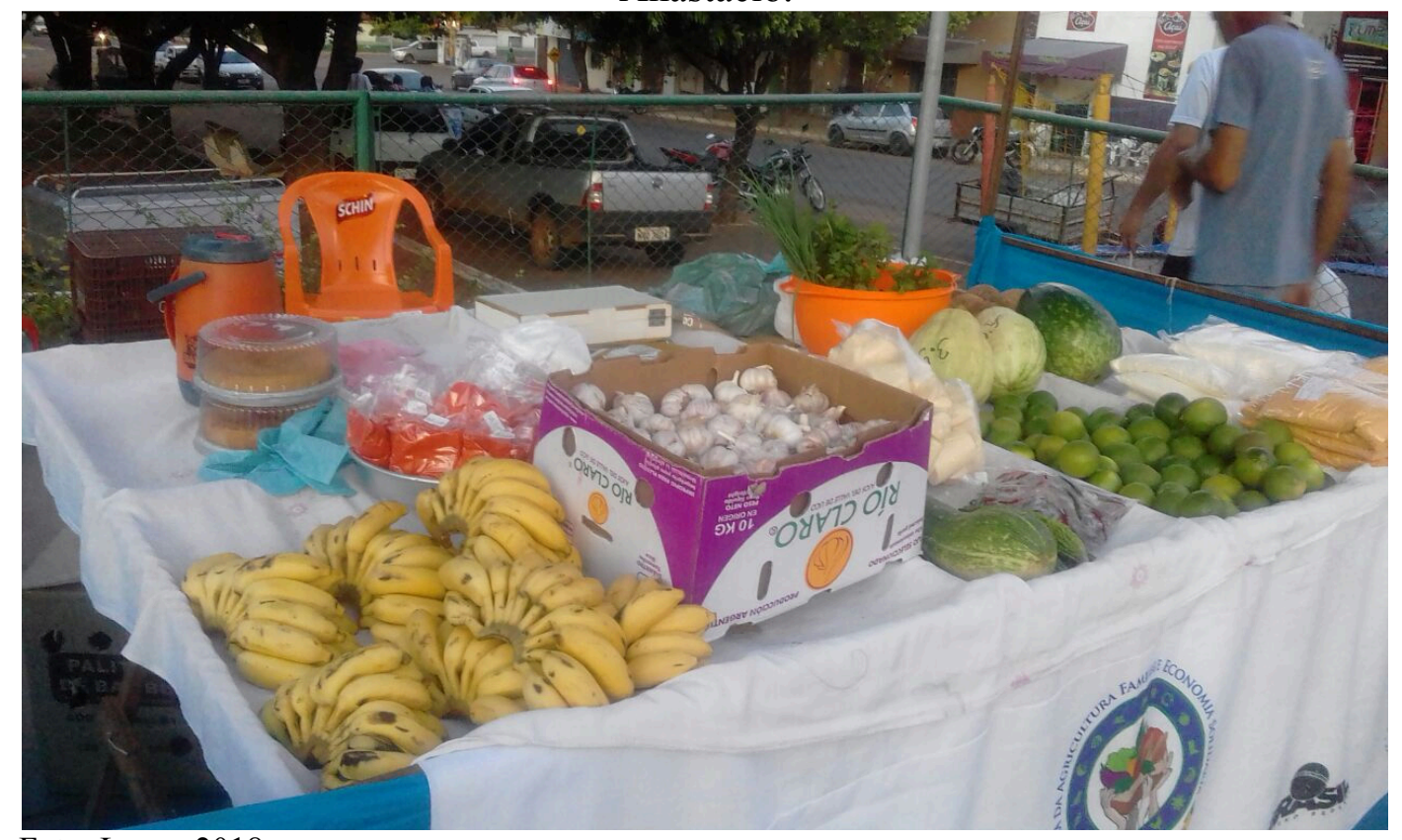

Foto: Leme, 2018.

Foto 03: Farinha de mandioca produzida por camponês da Colônia Pulador, disposta para venda em açougue da cidade de Anastácio-MS.

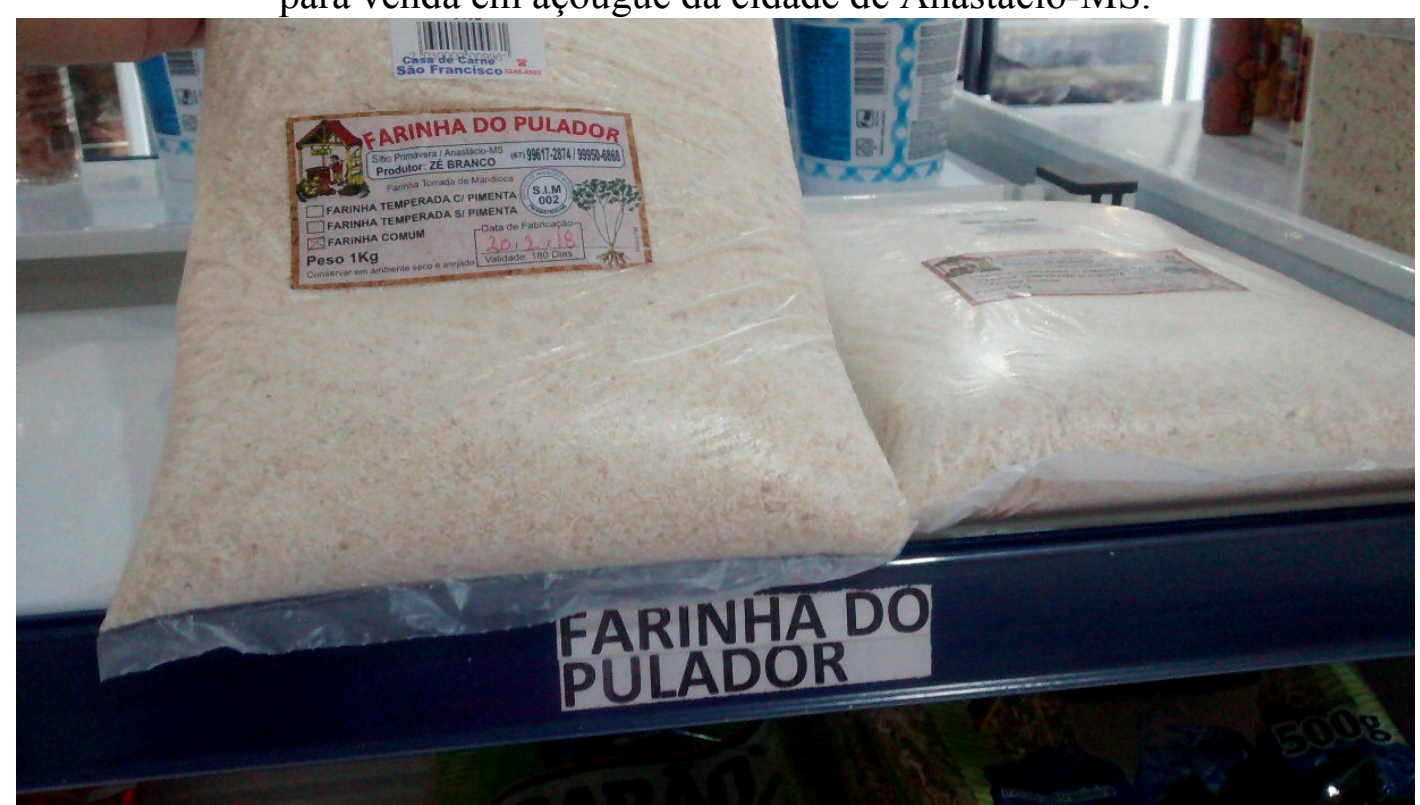

Foto: Leme, 2018. 
Analisamos na Colônia, uma interação parcial com o mercado capitalista. Essa interação se dá, dentre elas, a partir da compra de elementos para a unidade de produção (insumos e instrumentos de trabalho), e da compra de produtos que não são produzidos na unidade. Observamos uma relativa autonomia frente ao processo de comercialização dos produtos. A autonomia é maior, quando os camponeses vendem diretamente seu produto no mercado, sem a presença de intermediários.

Atualmente, a tradicional "Farinha de Mandioca do Pulador", é conhecida em toda a região. Mesmo com um número reduzido de produtores, é muito comum moradores urbanos se deslocarem até as unidades produtoras do Pulador para adquirir a farinha. A Farinha do Pulador pode ser encontrada nas versões tradicional, temperada com pimenta e temperada sem pimenta.

No que se refere à produção do leite, a presença de atravessadores que transportam o leite até o laticínio, indica o caráter da apropriação da renda da terra camponesa por outros setores. De acordo com as entrevistas, o atravessador paga $\mathrm{R} \$ 0,70$, no litro do leite. $\mathrm{Na}$ entrega em residências das cidades de Anastácio e Aquidauana, o leite é comercializado por R\$1,30, o litro.

Porém, nota-se a consciência dos camponeses frente a essa apropriação e o desenvolvimento de mecanismos internos para reverter esse processo exploratório. Uma das estratégias foi colocada em prática por uma das famílias entrevistadas:

...a gente tava entregando o leite para o laticínio. O preço do leite não tava compensando fazer a entrega, aí definimos que a gente não ia mais entregar o leite. Agora nós fazemos o queijo e entregamos em um açougue de Aquidauana. Hoje a renda do queijo fica em torno de R\$ 1.500 por mês, quando a gente entregava o leite, a renda era em torno de R\$ 600 por mês, melhorou bastante... (Entrevista realizada em $10 / 01 / 2018)$.

Percebe-se nesta estratégia adotada pela família camponesa a conquista de autonomia perante o capital. Nesse sentido, o camponês percebe o mecanismo de exploração da renda da terra pelo capital, e desenvolve maneiras de escapar dessa exploração.

A participação na Feira Municipal de Anastácio, possibilita a família camponesa uma maior autonomia na comercialização dos produtos, a entrega direta em mercados e residências na área urbana também revela os aspectos de uma maior autonomia para o 
campesinato, pois esses mecanismos de comercialização negam a exploração da renda da terra pelo mercado capitalista. No entanto, no que se refere a produção do leite na colônia, a presença de atravessadores que transportam o leite até os laticínios, indica o caráter da apropriação da renda da terra camponesa pelo setor capitalista.

Outro elemento de destaque nas entrevistas realizadas foi a consciência dos camponeses perante a necessidade de políticas públicas que beneficiem os camponeses da Colônia Pulador. Os camponeses destacaram a necessidade da formação de uma cooperativa para o recebimento do leite antes de ser encaminhado para o laticínio, e a importância de uma maior assistência rural, como a cedência de tratores e equipamentos para preparar o solo:

...a prefeitura devia ajuda mais os produtores, devia incentivar o pequeno produtor, ajudar com adubo, com assistência técnica para o corretivo de solo, trator para preparar a terra... hoje pra alugar um trator é $\mathrm{R} \$ 140$ a hora, nem todo mundo tem esse dinheiro pra alugar o trator...eu acho que eles deviam incentivar mais a nossa produção... (entrevista realizada em 11/01/2018).

...aqui a gente fica à mercê do laticínio, eles pagam o preço que eles querem, temos que aceitar o que é posto por eles, se decidimos não entregar o leite, tem que ver o que faz com leite aqui, a formação de uma cooperativa nossa, facilitaria aí poderíamos valorizar nossa produção... (entrevista realizada em 11/01/2018).

Fica evidente na fala do camponês a necessidade de políticas públicas que beneficiem a produção do campesinato da Colônia Pulador. As políticas públicas devem estar direcionadas para a reprodução da família camponesa, através de subsídios para auxiliar na produção e comercialização dos produtos, garantindo assim, mais autonomia do campesinato frente a expansão das relações capitalistas no campo.

Verifica-se que ao longo do processo de formação territorial da Colônia, houve a total ausência de políticas públicas para a região. De acordo com Mizusaki (2009), as políticas públicas aplicadas aos camponeses, tendem ao fracasso pelo fato de desconsiderarem o campesinato como classe social. As políticas, quando existem, estão voltadas para a tentativa de integrar o camponês ao mercado capitalista, sob um viés produtivista, e acabam por desconsiderar o modo de vida desses sujeitos.

Acredita-se que a produção camponesa, fortalece o campesinato local e possibilita mais qualidade de vida no campo e na cidade, com a manutenção de pessoas no campo 
produzindo alimentos para a família e para a comercialização no mercado local. Entendese que as políticas públicas, devem favorecer a produtividade do campesinato, considerando o modo de vida camponês, suas relações de produção e trabalho que diferem das relações empreendidas sob a lógica capitalista de produção.

Para Ploeg (2009, p. 30), os níveis de produtividades do campesinato podem ser ampliados, se esses sujeitos tiverem espaço sociopolítico e econômico. Contudo, se os camponeses não tiverem esse espaço ou se ele estiver cada vez mais sendo limitado, estaremos diante de sujeitos em via de expropriação, por não conseguirem produzir e vender seus produtos. "Isso significa que aqueles que tentam promover o campesinato devem contribuir o quanto possivel para a ampliação da autonomia, assim como apoiar as ações voltadas para o fortalecimento da produção e da sustentabilidade”.

Atualmente, quase um século após o início das primeiras migrações para a Colônia Pulador, muitos desafios ainda estão postos para esses camponeses. Porém, mesmo com a ausência de políticas públicas para a região, os camponeses se erguem na luta para permanência na terra. Os desafios estão na busca de meios para produzir, assistência técnica para as correções no solo, estratégias de comercialização, entre muitas outras. A luta camponesa é contínua, e mesmo que muitos desistam da luta, outros estão dispostos a permanecer, e muitos outros disposto a entrar, a resistência caracteriza o processo de reprodução do campesinato da Colônia Pulador.

\section{Considerações finais}

A expansão do capitalismo no campo tem provocado alterações nas relações de trabalho a ponto de indicar o fim dos camponeses, em virtude da grande expansão do capital industrial sobre o campo. Entretanto, verifica-se a permanência desses sujeitos, que tem a terra como terra de trabalho e não terra de negócio, desenvolvendo várias estratégias de resistência para permanecerem na terra.

Os camponeses da Colônia Pulador trabalham na terra utilizando a mão-de-obra familiar, e desenvolvem várias estratégias para permanecerem como camponeses, garantindo assim uma autonomia relativa frente a expansão das relações capitalista de produção, porém torna-se fundamental o papel de políticas públicas para incentivar a 
produção camponesa, visto que essa produção é destinada ao mercado local sendo fundamental para garantir a soberania alimentar da população local.

Torna-se fundamental indicar a importância do campesinato para garantir a produção, comercialização e consumo de produtos produzidos localmente, diminuindo a dependência de produtos vindos de outras regiões do país ou de outros países.

Desta forma, a resistência camponesa representa um mecanismo contra a expropriação e proletarização do campesinato, contrariando a tese a extinção do campesinato frente ao avanço do capitalismo no campo. Os camponeses buscam na contradição do modo de produção capitalista estratégias para a continuidade do trabalho camponês.

\section{Notas}

1 Este artigo refere-se a resultados parciais da pesquisa de doutorado intitulada: "Modalidades de reprodução camponesa nas colônias Pulador, município de Anastácio-MS e Jamic, município de TerenosMS", desenvolvida no Programa de Pós Graduação em Geografia pela Universidade Federal da Grande Dourados (UFGD).

\section{Referências}

CHAYANOV, Alexander V. La organizacion de la unidad economic campesina. Trad. R.M. Russivich. Buenos Aires: Nueva vision SAIC, 1974.

CAMACHO, Rodrigo Simão. Por uma Agricultura Camponesa. Cadernos de Agroecologia, v.11, p.1 - 12, 2016.

CAMACHO, Rodrigo Simão. Algumas considerações sobre o modo de vida camponês. Fórum Ambiental da Alta Paulista, v.10, p.1 - 16, 2014a.

CAMACHO, Rodrigo Simão. Paradigmas em disputa na educação do campo. Tese (Doutorado em Geografia) - Faculdade de Ciências e Tecnologia, Universidade Estadual Paulista, Presidente Prudente, 2014b.

FABRINI, João Edmilson. A escala da luta e resistência camponesa. Geosul, Florianopolis, v.21, n.42, p63-91, jul./dez. 2006.

FERNANDES, Bernardo Mançano. Questão agrária: conflitualidade e desenvolvimento territorial: In: Luta pela Terra, Reforma Agrária e Gestão de conflitos no Brasil. Antônio Márcio Buainain (Editor). Editora da Unicamp, 2007.

KAUSTKY, Karl. A questão agrária. Tradução de C. Iperoig. 3.ed. São Paulo: Proposta, 1980. 329 p. 
LÊNIN, Vladimir Ilyich. O Desenvolvimento do capitalismo na Rússia. São Paulo: Nova Cultural, 1985. 402 p.

MARQUES, Marta Inez Medeiros. A atualidade do uso do conceito de camponês. Revista Nera, Presidente Prudente: Unesp, ano 11, n. 12, p. 57-67, jan./jun. 2008.

MARTINS, José de Souza. Os Camponeses e a Política no Brasil. 4 ed., Petrópolis: Vozes. 1990.

MIZUSAKI, Márcia Yukari. Território e reestruturação produtiva na avicultura. Dourados, MS: Editora UFGD, 2009.

MOURA, Margarida Maria. Camponeses. São Paulo: Ática, 1988.

OLIVEIRA, Ariovaldo Umbelino de. Agricultura e indústria no Brasil. In. Boletim Paulista de Geografia. São Paulo: AGB, 1981. n 58.

OLIVEIRA, Ariovaldo Umbelino de. A Agricultura Camponesa no Brasil. São Paulo: Contexto, 1991.

OLIVEIRA, Ariovaldo Umbelino de. Agricultura Brasileira: desenvolvimento e contradições. São Paulo: mimeo: FFLCH/USP, 1992.

OLIVEIRA, Ariovaldo Umbelino de. Geografia agrária: perspectivas no início do século XXI. In: OLIVEIRA, Ariovaldo Umbelino de; MARQUES, Marta Inês Medeiros (Org.). O campo no século XXI: território de vida, de luta e de construção da justiça social. São Paulo: Casa amarela; Paz e Terra, 2004. p. 27-64.

PLOEG, Jan Douwe van der. Sete teses sobre a agricultura camponesa. In. PETERSEN, Paulo (Org.). Agricultura familiar camponesa na construção do futuro. Rio de Janeiro: AS-PTA, 2009, p. 17-32. Disponível em: $<$ http://aspta.org.br/wpcontent/uploads/2011/05/N\%C3\%BAmeroespecial.pdf>. Acesso em: out. 2018.

SHANIN, Teodor. Lições Camponesas. In: PAULINO, E. T. e FABRINI, J. E. (org). Campesinato: Territórios em disputa. São Paulo: Expressão Popular, 2008. p. 23-47.

TAVARES DOS SANTOS, José Vicente. Colonos do Vinho. São Paulo: Hucitec, 1978. $182 \mathrm{p}$.

Recebido em 28/05/2018.

Aceito para publicação em 12/02/2019. 